Check for updates

Cite this: RSC Adv., 2019, 9, 12555

Received 28th February 2019

Accepted 10th April 2019

DOI: 10.1039/c9ra01539f

rsc.li/rsc-advances

\section{Black titania nanotubes/spongy graphene nanocomposites for high-performance supercapacitors}

\author{
Dalia M. El-Gendy, ${ }^{a b}$ Nabil A. Abdel Ghany (D) *b and Nageh K. Allam (D) *a
}

A simple method is demonstrated to prepare functionalized spongy graphene/hydrogenated titanium dioxide $\left(\mathrm{FG}-\mathrm{HTiO}_{2}\right)$ nanocomposites as interconnected, porous 3-dimensional (3D) network crinkly sheets. Such a 3D network structure provides better contact at the electrode/electrolyte interface and facilitates the charge transfer kinetics. The fabricated $\mathrm{FG}-\mathrm{HTiO}_{2}$ was characterized by $\mathrm{X}$-ray diffraction (XRD), FTIR, scanning electron microscopy (FESEM), Raman spectroscopy, thermogravimetric analysis (TGA), UV-Vis absorption spectroscopy, and transmission electron microscopy (TEM). The synthesized materials have been evaluated as supercapacitor materials in $0.5 \mathrm{M} \mathrm{H}_{2} \mathrm{SO}_{4}$ using cyclic voltammetry (CV) at different potential scan rates, and galvanostatic charge/discharge tests at different current densities. The FG- $\mathrm{HTiO}_{2}$ electrodes showed a maximum specific capacitance of $401 \mathrm{~F} \mathrm{~g}^{-1}$ at a scan rate of $1 \mathrm{mV}$ $\mathrm{s}^{-1}$ and exhibited excellent cycling retention of $102 \%$ after 1000 cycles at $100 \mathrm{mV} \mathrm{s}$. The energy density was $78.66 \mathrm{~W} \mathrm{~h} \mathrm{~kg}^{-1}$ with a power density of $466.9 \mathrm{~W} \mathrm{~kg}^{-1}$ at $0.8 \mathrm{~A} \mathrm{~g}^{-1}$. The improved supercapacitor performance could be attributed to the spongy graphene structure, adenine functionalization, and hydrogenated titanium dioxide.

\section{Introduction}

Electrochemical supercapacitors have attracted great attention lately due to their high power density, reversibility, and long cycle life. ${ }^{1}$ Based on their charge storage mechanism, supercapacitors can be classified into two types: electric double-layer capacitors (EDLCs) and pseudocapacitors. While EDLCs store energy physically by charge accumulation at the electrode/ electrolyte interface, ${ }^{2}$ pseudocapacitors (battery-type) store energy chemically by fast and reversible faradaic reactions at the electrode surface. ${ }^{3}$ The pseudocapacitive materials, such as metal oxides and conducting polymers, ${ }^{4,5}$ can achieve relatively higher capacitance than EDLCs. However, they are limited by the low cyclability due to the structural degradation of the electrodes during the faradaic reactions. ${ }^{6}$ To this end, carbonaceous materials loaded with metal oxides or polymers are widely investigated as alternatives, ${ }^{7-9}$ including carbon nanotubes (CNTs), activated carbons (AC), graphite, graphene oxide, and graphene. These materials have been actively used due to their advantages, including ease of fabrication and workability under a wide temperature range. Different modifications have applied to those materials to increase their surface area and

${ }^{a}$ Energy Materials Laboratory, School of Sciences and Engineering, The American University in Cairo, New Cairo 11835, Egypt. E-mail: Nageh.allam@aucegypt.edu ${ }^{b}$ Physical Chemistry Department, National Research Centre, Dokki, Cairo 12622, Egypt.E-mail:na_manakhly@yahoo.co.uk tailor their pore size distribution (PSD), resulting in an improvement of their energy and power densities. ${ }^{\mathbf{8} 9}$

Specially, graphene-based materials are given much consideration as an effective electrode material owing to their unique properties, such as high specific surface area, excellent chemical stability, electrical and mechanical properties, and the large scale production of graphene. ${ }^{\mathbf{1 0 - 1 2}}$ To this end, the Hummers' method is widely used to produce graphene oxides (GO). ${ }^{\mathbf{1 3}}$ However, the poor electrical conductivity of GO reduces the efficiency of charge transfer and reduces long cycle life. ${ }^{\mathbf{1 4}}$ These problems can be overcome by removing partially the $\mathrm{O}$ containing groups via chemical reduction or by thermal annealing. ${ }^{15,16}$ Also, by using reducing agents such as (hydrazine, dimethyl hydrazine, and $\mathrm{NaBH}_{4}$ ) to prepare the graphene. This method is harmful to the environment and the resulted graphene has a strong tendency to restack due to the $\pi-\pi$ interactions. ${ }^{17,18}$ Therefore, an easy, eco-friendly process to reduce GO is urgently required. Carbon based materials have the high specific surface area, high electrical conductivity, and highly stable. But, carbon based material suffer from low energy density. Compared to, transition metal oxides have high specific capacitance and energy densities. For examples ruthenium, oxide-based materials used to supercapacitors application have high specific capacitance but are more expensive than the other metal oxides such as $\mathrm{MnO}_{2}, \mathrm{Co}_{3} \mathrm{O}_{4}, \mathrm{TiO}_{2}$, and $\mathrm{SnO}_{2}$. Therefore, it is rational to combine low-cost metal oxides with carbon materials to obtain high energy density and high power density through the preparation of a composite. ${ }^{\mathbf{1 9 , 2 0}}$ 
Herein, a simple method is confirmed to prepare functionalized spongy graphene/hydrogenated titanium dioxide composites to prevent graphene sheets from restacking together, resulting in interconnected, porous 3D network crinkly sheets. Such 3D network structure provides better contact at the electrode/electrolyte interface and facilitates the charge transfer kinetics. Functionalized spongy graphene/ hydrogenated titanium dioxide has been produced by functionalization of the graphene oxide with adenine. Afterward hydrothermal, functionalized spongy graphene oxide (FGO) with $\mathrm{HTiO}_{2}$ was obtained, which helps to prevent the stacking between graphene interlayers. The FG- $\mathrm{HTiO}_{2}$ electrodes showed high performance upon their use in electrochemical capacitor assembly.

\section{Experimental methods}

\section{Materials}

Graphite powder $(<20 \mu \mathrm{m})$ and Nafion 117 solution (5\%) were purchased from Sigma Aldrich. Sulphuric acid $\left(\mathrm{H}_{2} \mathrm{SO}_{4}, 99 \%\right)$ from Sham Lab. Hydrogen peroxide $\left(\mathrm{H}_{2} \mathrm{O}_{2}, 30 \% \mathrm{w} / \mathrm{v}\right)$ from LOBA Chemie, absolute ethanol and $\mathrm{HCl}$ (33\%) were purchased from El-Nasr Pharmaceutical Company, Egypt. Finally, potassium permanganate $\left(\mathrm{KMnO}_{4}, 99 \%\right)$, from Arabic Laboratory Equipment Co., Ti foils (99.5\% purity, $0.1 \mathrm{~mm}$ thickness) were purchased from Sigma Aldrich and, before anodization, cleaned by sonicating in acetone, ethanol, and followed by washing with deionized (DI) water and drying in air. The electrolytes were $\mathrm{HClO}_{4}$ purchased from Sigma Aldrich, and all the solutions were prepared from reagent-grade chemicals and deionized water. Adenine (Merck) was used directly without further purification. Distillated water was used for washing the products.

\section{Synthesis of spongy graphene oxide (SGO)}

GO was prepared from natural graphite using a modified Hummers' method..$^{21}$ In a typical experiment, graphite $(1.5 \mathrm{~g})$, $\mathrm{NaNO}_{3}(1.5 \mathrm{~g})$ and $\mathrm{H}_{2} \mathrm{SO}_{4}(70 \mathrm{ml})$ were mixed and stirred in an ice bath. Subsequently, $9 \mathrm{~g}$ of $\mathrm{KMnO} 4$ were added slowly. The reaction mixture was warmed to $40{ }^{\circ} \mathrm{C}$ and stirred for $1 \mathrm{~h}$. Water $(100 \mathrm{ml})$ was then added and the temperature was increased to $90{ }^{\circ} \mathrm{C}$ for $30 \mathrm{~min}$. Finally, $300 \mathrm{ml}$ of water were added slowly, followed by the slow addition of $10 \mathrm{ml}$ of $30 \% \mathrm{H}_{2} \mathrm{O}_{2}$. The reaction mixture was filtered and washed with $0.1 \mathrm{M} \mathrm{HCl}$ and water. The GO precipitate was dispersed in a water/methanol $(1: 5)$ mixture and purified with three repeated centrifugation steps at $10000 \mathrm{rpm}$ for $30 \mathrm{~min}$. The purified sample was dispersed in deionized water and centrifuged at $2500 \mathrm{rpm}$ and finally washed with deionized water and sonicated for 1 hour to obtain highly exfoliated graphene oxide. The GO precipitate was dispersed in water/methanol mixture and purified with repeated centrifugation steps at $10000 \mathrm{rpm}$ for $30 \mathrm{~min}$. Note that washing with $0.1 \mathrm{M} \mathrm{HCl}$ and water resulted in highly exfoliated GO sheets. To prepare SGO, GO solution $\left(4 \mathrm{mg} \mathrm{l}^{-1}\right)$ was frozen at $-18{ }^{\circ} \mathrm{C}$ for 2 days. After the GO solution was completely frozen, the tube was peregrinated to a freeze-dryer and dried at a temperature of $-53{ }^{\circ} \mathrm{C}$ and a pressure of $10 \mathrm{~Pa}$ for 3 days. $^{22}$

\section{Preparation of adenine-functionalized graphene oxide}

GO $(0.1 \mathrm{~g})$ was dispersed in distilled water $(10 \mathrm{ml})$, then $(0.3 \mathrm{~g})$ adenine and equimolar amount of $\mathrm{NaOH}$ in distilled water (10 $\mathrm{ml}$ ) were added. The mixture was stirred for $24 \mathrm{~h}$. The resulted precipitate was centrifuged, washed well with water/ethanol mixture and finally dried at $60{ }^{\circ} \mathrm{C} .{ }^{23}$

\section{Preparation of $\mathrm{TiO}_{2}$ and hydrogenated $\mathrm{TiO}_{2}\left(\mathrm{H}-\mathrm{TiO}_{2}\right)$ nanotubes powder}

Pieces Ti foil $(1 \mathrm{~cm} \times 1 \mathrm{~cm})$ was anodized in $0.1 \mathrm{M} \mathrm{HClO}_{4}$ aqueous electrolyte in a two-electrode cell with the titanium foil as the working electrode and a platinum foil as the counter electrode at $25{ }^{\circ} \mathrm{C}$ and a constant potential of $20 \mathrm{~V}$. Finally, the foil was converted into $\mathrm{TiO}_{2}$ nanotube powder. Later, the asgrown $\mathrm{TiO}_{2}$ nanotube powder (white precipitate) was washed several times with DI water, collected by centrifugation, and lastly oven-dried at $60{ }^{\circ} \mathrm{C}$ about $15 \mathrm{~h} .{ }^{24}$ Eventually, a white powder was obtained and to produce well-defined crystalline structures, sample A was annealed at $550{ }^{\circ} \mathrm{C}$ under air, while sample B was annealed at $550{ }^{\circ} \mathrm{C}$ under hydrogen to compare structures of powders for $2 \mathrm{~h}$ with a heating rate of $30^{\circ} \mathrm{C} \mathrm{min}{ }^{-1}$ using Advantec KM-100 electric muffle furnaces.

\section{Preparation of functionalized graphene-hydrogenated titanium (FG-HTiO ${ }_{2}$ )}

The functionalized graphene-hydrogenated $\mathrm{TiO}_{2}$ was prepared by the hydrothermal reduction method. Briefly a specific amount of functionalized graphene oxide powder with hydrogenated $\mathrm{TiO}_{2}$ equivalent to 10, 20, 25 and $30 \mathrm{wt} \%$ from FGO mass were added to a $100 \mathrm{ml}$ conical flask containing $40 \mathrm{ml}$ of deionized water and sonicated for $30 \mathrm{~min}$ to obtain a homogeneous dispersion; the samples were named as FG-HT1, FG-HT2, FG-HT3 and FG-HT4, respectively. The solutions were transferred to a Teflon-lined autoclaves and heated at $170{ }^{\circ} \mathrm{C}$ for $8 \mathrm{~h}$, and then left to cool at room temperature to get grey product. These products were washed several times with deionized water and collected through centrifugation. Finally, the solid products were dried in an oven at $60^{\circ} \mathrm{C}$. The steps are summarized in Scheme 1.

\section{Preparation of electrodes and electrochemical measurements}

Glassy carbon (GC) electrode (5.0 mm diameter) was polished with alumina nanopowder and rinsed with deionized water. Fresh dispersion of the sample was prepared for each experiment by dispersing $5.0 \mathrm{mg}$ of the FG powder in $0.5 \mathrm{ml}$ Nafion 117 solution (1\%) by ultra-sonication for $30 \mathrm{~min}$. Then $10 \mu \mathrm{l}$ suspension of the material was cast onto the surface of the electrode with a micropipette, finally, the working electrode was dried at $60{ }^{\circ} \mathrm{C}$ for $10 \mathrm{~min}$ and left to cool down. All the electrochemical measurements were done in a three-electrode system: where the working electrode was made from a glassy carbon disk, the standard calomel electrode (SCE) and platinum wire were used as reference and counter electrodes, respectively. The electrochemical measurements were carried out in $0.5 \mathrm{M}$ $\mathrm{H}_{2} \mathrm{SO}_{4}$ using Auto lab-302N electrochemical workstation 


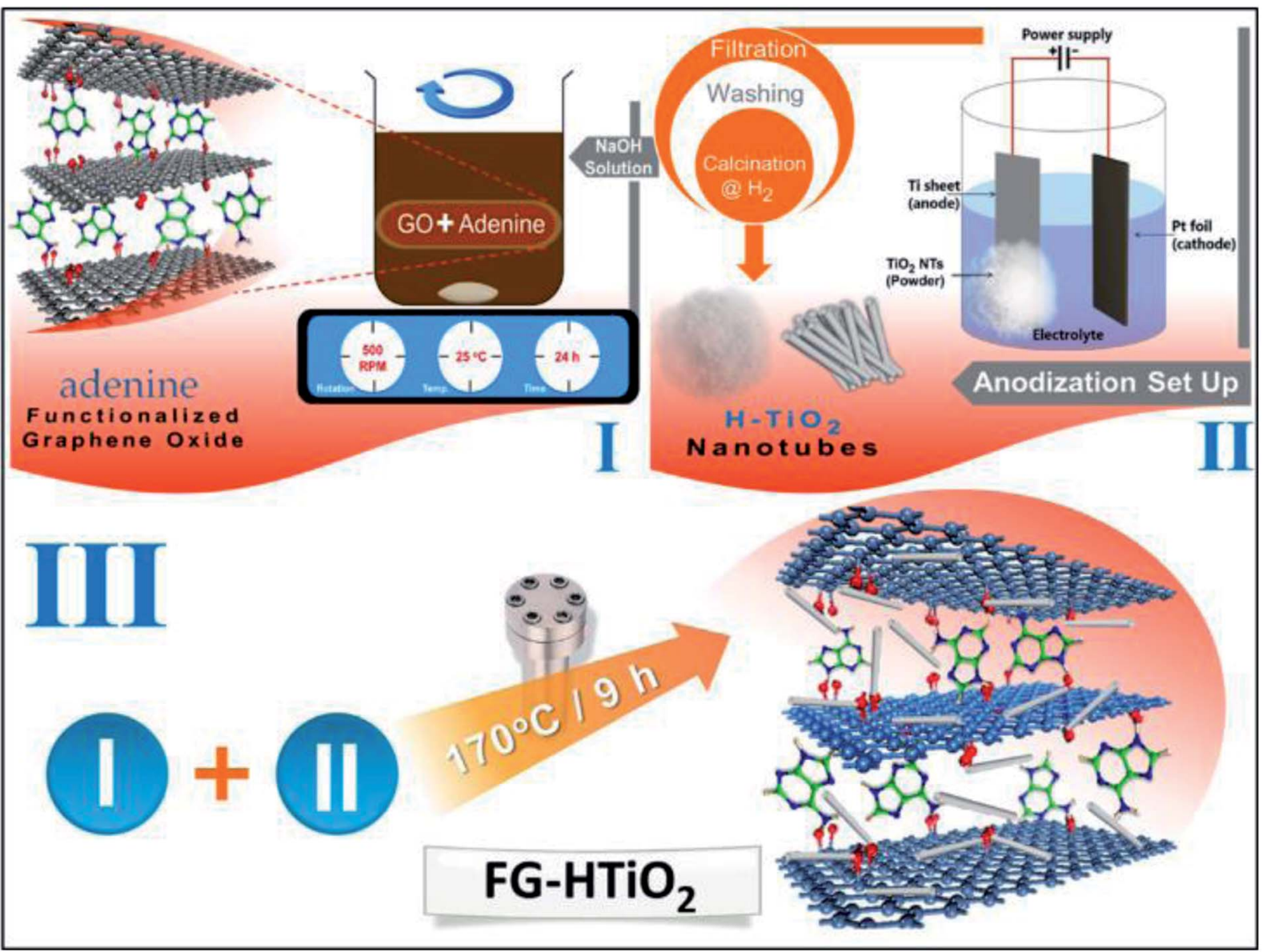

Scheme 1 Stepwise preparation of $\mathrm{FG}-\mathrm{HTiO}_{2}$.

(Metrohm). The cyclic voltammetry (CV) measurements were done in the potential range -0.2 to $1 \mathrm{~V}$ at various scan rates (1$100 \mathrm{mV} \mathrm{s}^{-1}$ ). Galvanostatic charge/discharge measurements were run from -0.2 to $1 \mathrm{~V}$ at current densities of $0.8,1,2$, $3, \mathrm{~A} \mathrm{~g}^{-1}$.

\section{Characterization techniques}

The crystal structure of the prepared materials was examined by X-ray diffraction (XRD, XPERT-PRO-Analytical) with $\mathrm{Cu} \mathrm{K} \alpha$ radiation $(\lambda=1.54 \AA)$. The surface morphology was investigated by field-emission scanning electron microscope (FESEM-Zeiss SEM Ultra-60). The morphology of the samples was investigated using high-resolution transmission electron microscope (HRTEM, JOEL JEM-2100) operating at an accelerating voltage of $120 \mathrm{kV}$. The infrared (IR) spectra were recorded using a JASCO spectrometer (FT/IR-6300 type A) in the range $400-4000 \mathrm{~cm}^{-1}$. $\mathrm{UV} / \mathrm{Vis}$ spectrophotometric measurements were made using a Shimadzu 2040 spectrophotometer. Raman measurements were performed using a micro-Raman microscope with an excitation laser beam wavelength of $325 \mathrm{~nm}$. The weight loss of the samples was collected by TGA thermal analyzer (TA TGAQ500) from room temperature to $800{ }^{\circ} \mathrm{C}$ at a heating rate $10{ }^{\circ} \mathrm{C} \min ^{-1}$ in nitrogen atmosphere, the time-dependent anodization currents were recorded using a computer controlled Keithley 2000 multimeter and Advantec KM-100 electric muffle furnaces.

\section{Results and discussion}

Fig. 1 shows FESEM images of the fabricated materials. Fig. 1a depicts the surface of the fabricated spongy graphene oxide (SGO), indicating a great increase in the thickness of the layers, which is possibly due to the formation of oxygen groups in the basal plane of graphene. Upon the addition of adenine, Fig. 1b, the graphene becomes more exfoliated with further increase in volume, resulting in flake-like structure with wrinkled edges and crumbled graphene morphology. Fig. 1c shows typical SEM images of the side and close-up top view of the nanotubes powder prepared in $\mathrm{HClO}_{4}$ electrolyte by rapid breakdown anodization. The tubes are well-arranged and produce very promptly in dense bundles of approximately $20-25 \mu \mathrm{m}$ in length with average nanotube diameter of $24 \mathrm{~nm}$. Fig. 1d shows an FESEM image of the hydrogenated titanium dioxide nanotubes $\left(\mathrm{H}-\mathrm{TiO}_{2} \mathrm{NTs}\right)$ grown on FG. The intercalation of $\mathrm{H}^{-} \mathrm{TiO}_{2}$ nanotubes between graphene layers plays an effective role to accumulate a large amount of ion salts on the surface of the electrode. Moreover, this unique morphology is useful to prevent the aggregation of the graphene sheets. The EDS 

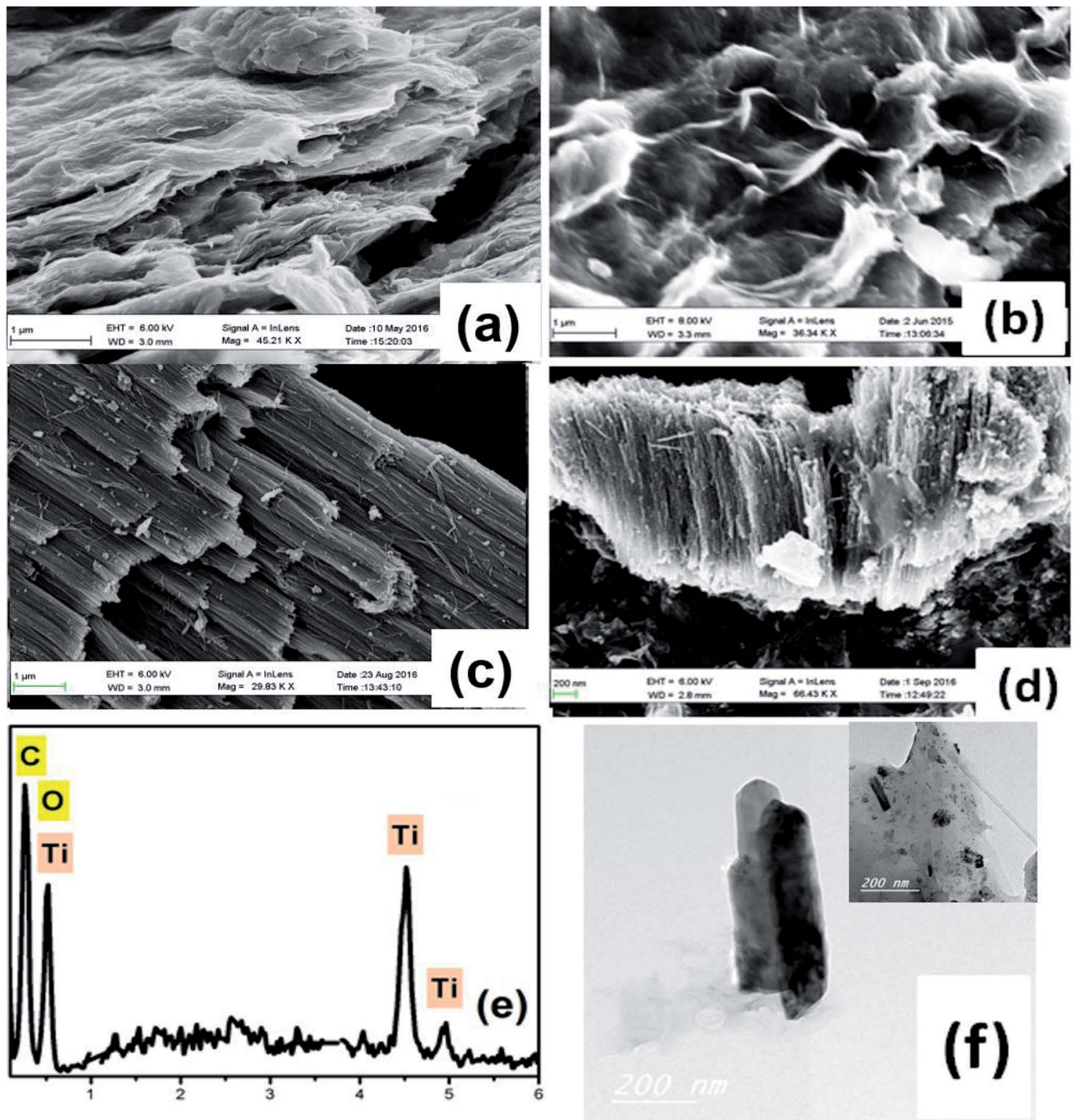

Fig. 1 FESEM images of (a) spongy GO, (b) FGO, (c) $\mathrm{HTiO}_{2}$, (d) $\mathrm{FG}-\mathrm{HTiO}_{2}$, (e) EDS image and, (f) the TEM image of $\mathrm{FG}-\mathrm{HTiO}$, of the functionalize graphene-hydrogenated $\mathrm{TiO}_{2}$ hybrid nanostructure.

spectrum of the graphene-hydrogenated $\mathrm{TiO}_{2}$ hybrid nanocomposite is shown in Fig. 1e, indicating the presence of carbon (C), titanium (Ti), and oxygen (O) elements. The Ti and $\mathrm{O}$ elements originated from the $\mathrm{TiO}_{2}$ nanoparticles, and the $\mathrm{C}$ was contributed by the graphene nanosheets. The corresponding TEM images, Fig. 1f showing the graphene-hydrogenated $\mathrm{TiO}_{2}$ hybrid nanostructure is a smooth and transparent surface with a nanotubular structure of $\mathrm{TiO}_{2}$ nanotubes.

Fig. 2a shows the XRD pattern of pristine and $\mathrm{H}: \mathrm{TiO}_{2}$ samples, revealing major peaks at $2 \Theta$ of $25.337 .84,48.07,53.95$ and 55.10 , with $d$ of $3.51,2.37,1.89,1.69$, and $1.66 \AA$ corresponding to diffraction from (101), (044), (200), (105) and (211) planes of the tetragonal anatase $\mathrm{TiO}_{2}$ phase, respectively. Note that the hydrogenation process does not change the crystalline phase of $\mathrm{TiO}_{2}$. However, the intensity and the peaks of hydrogenated $\mathrm{TiO}_{2}$ is higher than that of pristine $\mathrm{TiO}_{2}$ and the crystallite size of $\mathrm{H}: \mathrm{TiO}_{2}(31.8 \mathrm{~nm})$ is larger than that of pristine $\mathrm{TiO}_{2}(23.6 \mathrm{~nm})$, indicating the creation of oxygen vacancies upon hydrogen annealing leading to the formation of $\mathrm{Ti}^{3+} .^{25}$ Fig. $2 \mathrm{~b}$ compares the XRD patterns of pristine graphite, SGO, FG, $\mathrm{HTiO}_{2}$ and $\mathrm{FG}_{-} \mathrm{HTiO}_{2}$. An intense peak centred at $2 \Theta=26.5^{\circ}$ was observed for graphite. The broad peak observed in the XRD pattern of SGO centred at $2 \Theta=12^{\circ}$ proves the formation of abundant oxygen-containing groups by the oxidation process. After functionalization and hydrothermal treatment, the SGO is reduced and converted into FG, as indicated by the new characteristic peak at $2 \theta=24.8^{\circ}$. Notably, in case of $\mathrm{HTiO}_{2}$ nanocomposite, the main peak appeared at $2 \theta=25.1^{\circ}$ indexed to the 

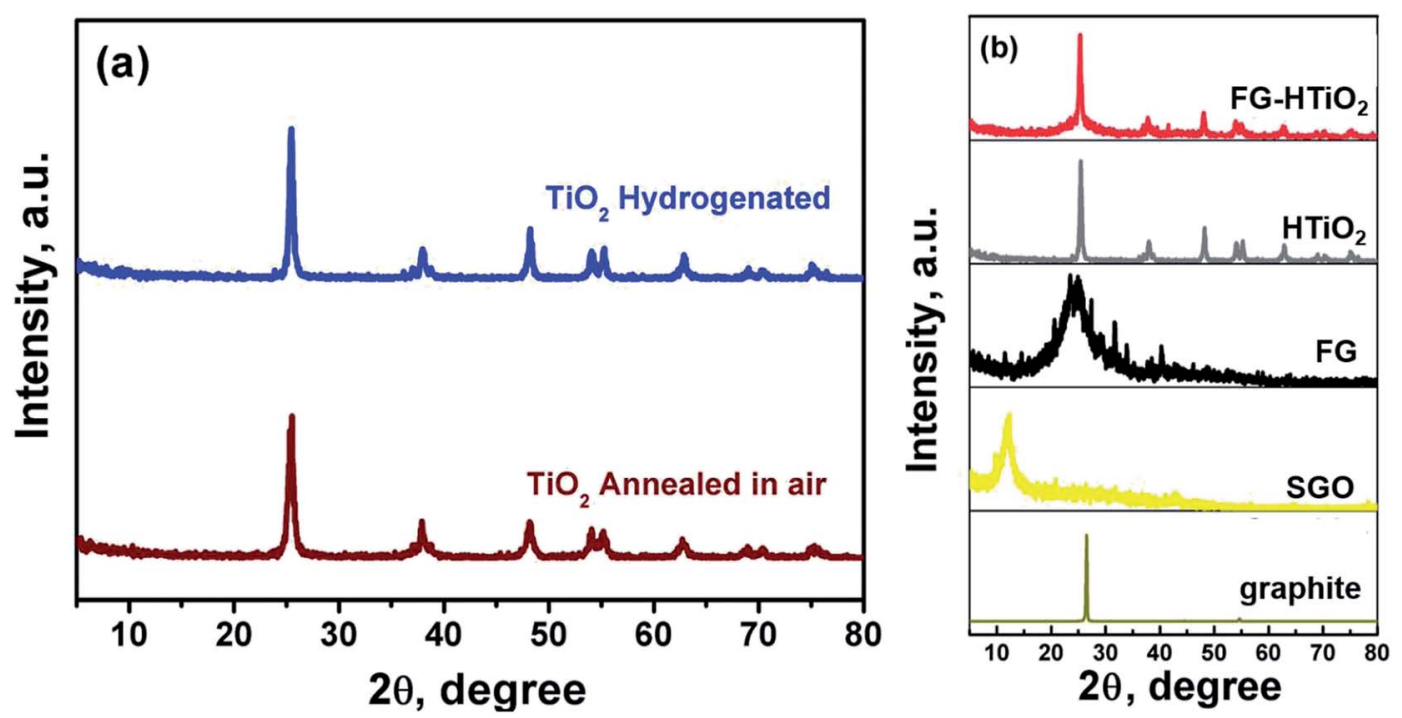

Fig. 2 XRD patterns of (a) air- and $\mathrm{H}_{2}$-annealed $\mathrm{TiO}_{2}$, and (b) pristine graphite, SGO, $\mathrm{FG}, \mathrm{HTIO}_{2}$ and $\mathrm{FG}-\mathrm{HTiO}_{2}$.

anatase phase of $\mathrm{TiO}_{2}$ and the main characteristic peak of FG at $25.0^{\circ}$ leads to an overlap with the (101) peak of anatase $\mathrm{TiO}_{2}$ at $25.1 .^{26}$

Fig. 3a compares the FTIR spectra of air and hydrogenannealed titania samples, showing similar absorption features in the range $500-4000 \mathrm{~cm}^{-1}$. Note the appearance of $\mathrm{OH}$ absorption bands near $3400 \mathrm{~cm}^{-1}$, owing to a bridging $\mathrm{OH}$ group (Fig. 3b). The peaks at $\sim 3700 \mathrm{~cm}^{-1}$ can be ascribed to the presence of the $\mathrm{O}-\mathrm{H}$ stretching and wagging modes. The strength of the terminal O-H mode is reduced when white $\mathrm{TiO}_{2}$ is changed to black $\mathrm{TiO}_{2}$ upon hydrogen annealing. Note that incorporated hydrogen into the $\mathrm{TiO}_{2}$ probably does not passivize a significant number of $\mathrm{O}$ dangling bonds as this would otherwise increase the absorption. ${ }^{26}$ Fig. $3 \mathrm{~b}$ also shows the spectra of GO, FGO, FG, and FG-HTiO 2 . The broad band centred around $3563 \mathrm{~cm}^{-1}$ can be assigned to $\mathrm{O}-\mathrm{H}$ stretching vibrations $\nu\left(\mathrm{OH}_{2}\right)$ attributed to adsorbed water. The other bands appeared at $1725 \mathrm{~cm}^{-1}$ can be attributed to the stretching vibrations $\nu(\mathrm{C}=\mathrm{O})$ of $\mathrm{COOH}$ group corresponding to carbonyl and carboxyl groups, the band at $1621 \mathrm{~cm}^{-1}$ attributed to in-plane vibration $(\mathrm{C}=\mathrm{C})$ from un-oxidized $\mathrm{sp}^{2} \mathrm{CC}$ bonds, the intense band at $1378 \mathrm{~cm}^{-1}$ corresponding to $\mathrm{O}-\mathrm{H}$ deformation of $\mathrm{C}-\mathrm{OH}$ group, and the band at $101 \mathrm{~cm}^{-1}$ attributed to $\nu(\mathrm{C}-\mathrm{O})$ stretching vibrations mode. ${ }^{26}$ The peak at $1725 \mathrm{~cm}^{-1}$ almost disappears and the peak emerged at $1637 \mathrm{~cm}^{-1}$ is characteristic of the $\mathrm{C}=\mathrm{O}$ stretching in the amide group, which cannot be found in the spectrum of GO. Stretching of the amide $\mathrm{C}-\mathrm{N}$ appears as a strong peak at $1188 \mathrm{~cm}^{-1}$. The peaks at 1560 and $1618 \mathrm{~cm}^{-1}$
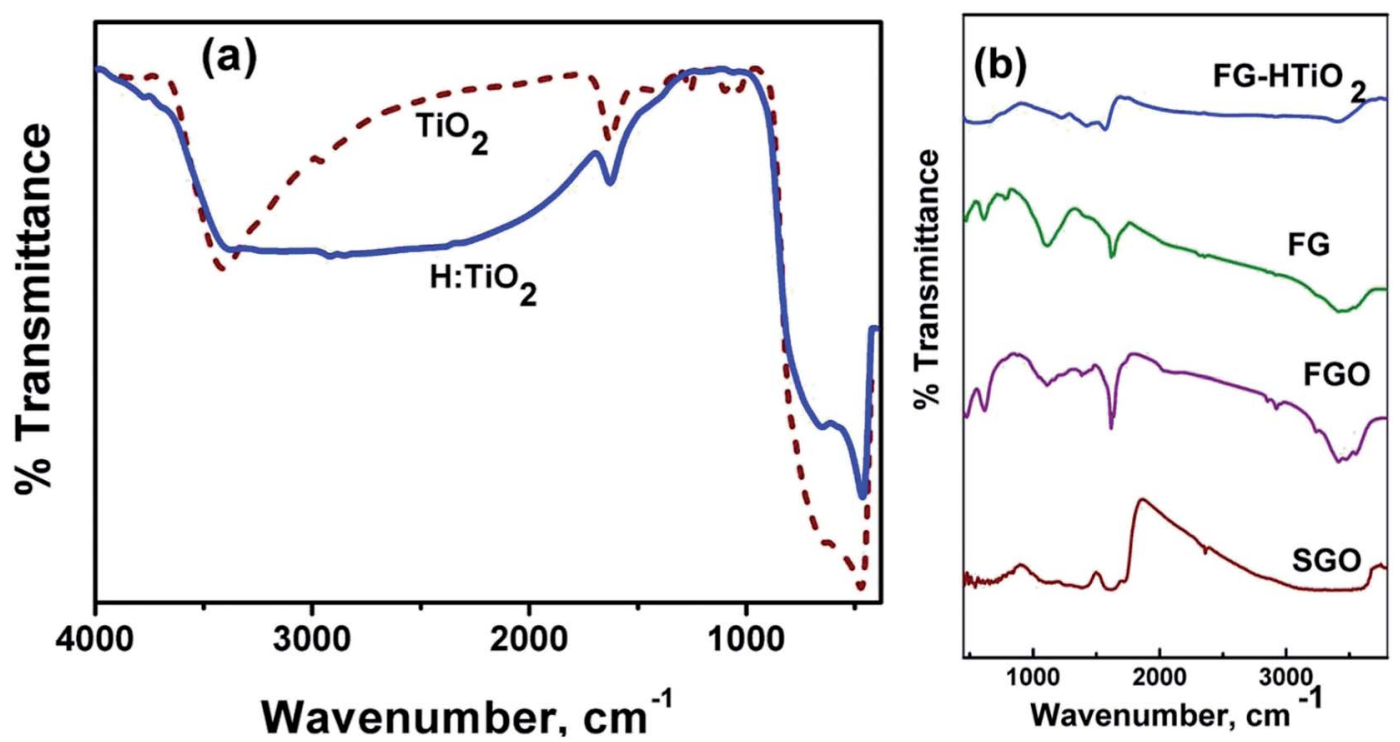

Fig. 3 FT-IR spectra of (a) air- and $\mathrm{H}_{2}$-annealed $\mathrm{TiO}_{2}$, and (b) pristine graphite, SGO, FG, $\mathrm{HTIO}_{2}$ and $\mathrm{FG}-\mathrm{HTiO}_{2}$. 
are characteristic of graphene vibration, and the peak attributed to the $\mathrm{OH}$ and $\mathrm{NH}$ stretching groups at $3475 \mathrm{~cm}^{-1}$ confirm the covalent functionalization of the neat graphite by adenine, assuring the successful functionalization process. The peak at $3415 \mathrm{~cm}^{-1}$ is attributed to $\mathrm{N}-\mathrm{H}$ stretching. ${ }^{27}$ These results demonstrate that adenine molecules were covalently bonded to GO by the amide linkage. The peak observed at $651 \mathrm{~cm}^{-1}$ corresponds to the Ti-O-Ti vibration of the $\mathrm{TiO}_{2}$ phase. ${ }^{28}$ For the graphene- $\mathrm{TiO}_{2}$ hybrid nanostructure, the intensities of the bands corresponding to the oxygen functional groups were reduced compared to GO, signifying the reduction of oxygen in the as-prepared graphene- $\mathrm{TiO}_{2}$ hybrid nanostructures. The strong band observed at $588 \mathrm{~cm}^{-1}$ indicated the Ti-O-C vibration. ${ }^{28}$ Note that the peak intensity of the $\mathrm{C}-\mathrm{O}$ and $\mathrm{C}-\mathrm{O}-\mathrm{C}$ (epoxide) groups, respectively, decreased in FGO, FG, and FG$\mathrm{HTiO}_{2}$ after the hydrothermal reduction with $\mathrm{HTiO}_{2}$ that resulted in $\mathrm{FG}-\mathrm{HTiO}_{2}$.

Raman spectroscopy is an effective process to examine the structural features of carbon-based materials. Fig. 4a shows the Raman spectra for air and hydrogen-annealed $\mathrm{TiO}_{2}$ electrodes. The peak intensity of hydrogenated $\mathrm{TiO}_{2}$ was lower than that of the air-annealed counterpart. The Raman peaks at $144 \mathrm{~cm}^{-1}$ and $636 \mathrm{~cm}^{-1}$ were shifted to a higher frequency, indicating the formation of oxygen vacancies due to the hydrogen annealing, in agreement with Liu et al. who proposed the formation of $\mathrm{Ti}^{3+} \cdot{ }^{29}$ The intensity ratio of the $\mathrm{D}$ and $\mathrm{G}$ bands $\left(I_{\mathrm{D}} / I_{\mathrm{G}}\right)$ is a convenient parameter for the determination of the $\mathrm{sp}^{2}$ domain size of carbon structures containing $\mathrm{sp}^{3}$ and $\mathrm{sp}^{2}$ domains. GO exhibited the $\mathrm{G}$ band at $1576 \mathrm{~cm}^{-1}$ and the $\mathrm{D}$ band at $1354 \mathrm{~cm}^{-1}$. While the intensity of the D band for $\mathrm{FG}-\mathrm{HTiO}_{2}$ was increased compared to that of SGO, the $\mathrm{G}$ band is still prominent and the $I_{\mathrm{D}} / I_{\mathrm{G}}$ ratio is 0.99 with the $I_{\mathrm{D}} / I_{\mathrm{G}}$ ratio of FG$\mathrm{HTiO}_{2}$ being 1.01. The higher $I_{\mathrm{D}} / I_{\mathrm{G}}$ ratio of FG-HTiO ${ }_{2}(1.01)$ than that of SGO (0.99) indicates the reduction in the size of the inplane $\mathrm{sp}^{2}$ domains. The notable bands located at $147\left(\mathrm{E}_{\mathrm{g}}\right), 402$
$\left(\mathrm{B}_{1 \mathrm{~g}}\right), 513\left(\mathrm{~A}_{1 \mathrm{~g}}\right)$, and $635\left(\mathrm{E}_{\mathrm{g}}\right)$ as well as the small peaks at $159 \mathrm{~cm}^{-1}$ are attributed to the intercalated $\mathrm{TiO}_{2}$ nanotubes with graphene. ${ }^{30,31}$

To evaluate the thermal stability of GO, FGO, FG and FG$\mathrm{HTiO}_{2}$, TGA analysis was performed by heating under $\mathrm{N}_{2}$ atmosphere to $800{ }^{\circ} \mathrm{C}$ at a rate of $10{ }^{\circ} \mathrm{C} \mathrm{min} \mathrm{m}^{-1}$, Fig. 5. At temperatures below $100{ }^{\circ} \mathrm{C}$, the mass loss can be related to the removal of adsorbed $\mathrm{H}_{2} \mathrm{O}$. For GO, it is thermally unstable and the mass loss occurs in three steps: the first step is detected below $110{ }^{\circ} \mathrm{C}$ that can be associated with vapor content and loss of interstitial $\mathrm{H}_{2} \mathrm{O}^{32}$ with a total mass loss of $\sim 8 \%$, the second stage is detected in the range $130-250{ }^{\circ} \mathrm{C}$ as a sharp drop peak that accounts for a mass loss of $\sim 65 \%$, owing to the decay of hydroxyl groups, presented water on GO, and carboxyl group to produce gases such as $\mathrm{H}_{2} \mathrm{O}$ and $\mathrm{CO}_{2}$. Note that $\mathrm{CO}_{2}$ is generally created because of the decomposition of carboxyl group due to

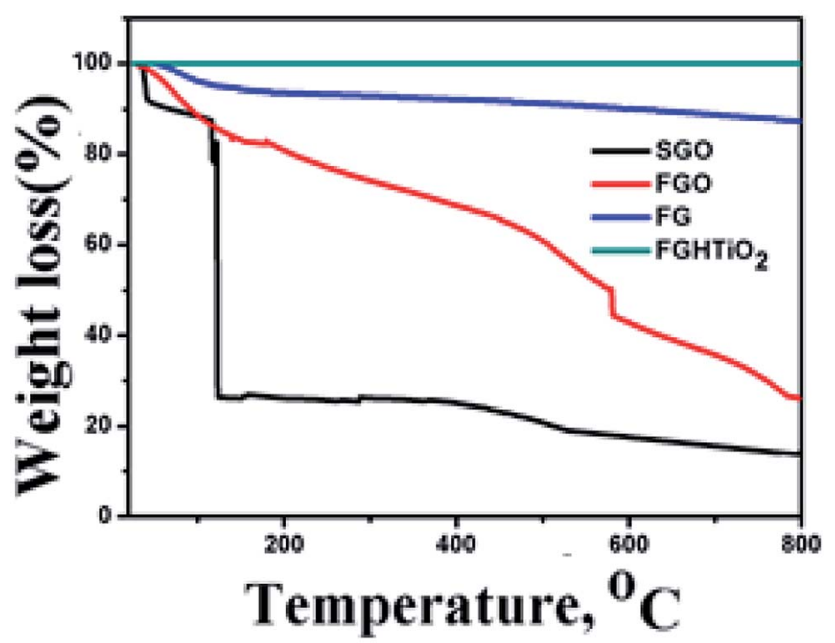

Fig. 5 TGA analysis of $\mathrm{SGO}, \mathrm{FGO}, \mathrm{FG}$ and $\mathrm{FG}-\mathrm{HTiO}_{2}$ samples.
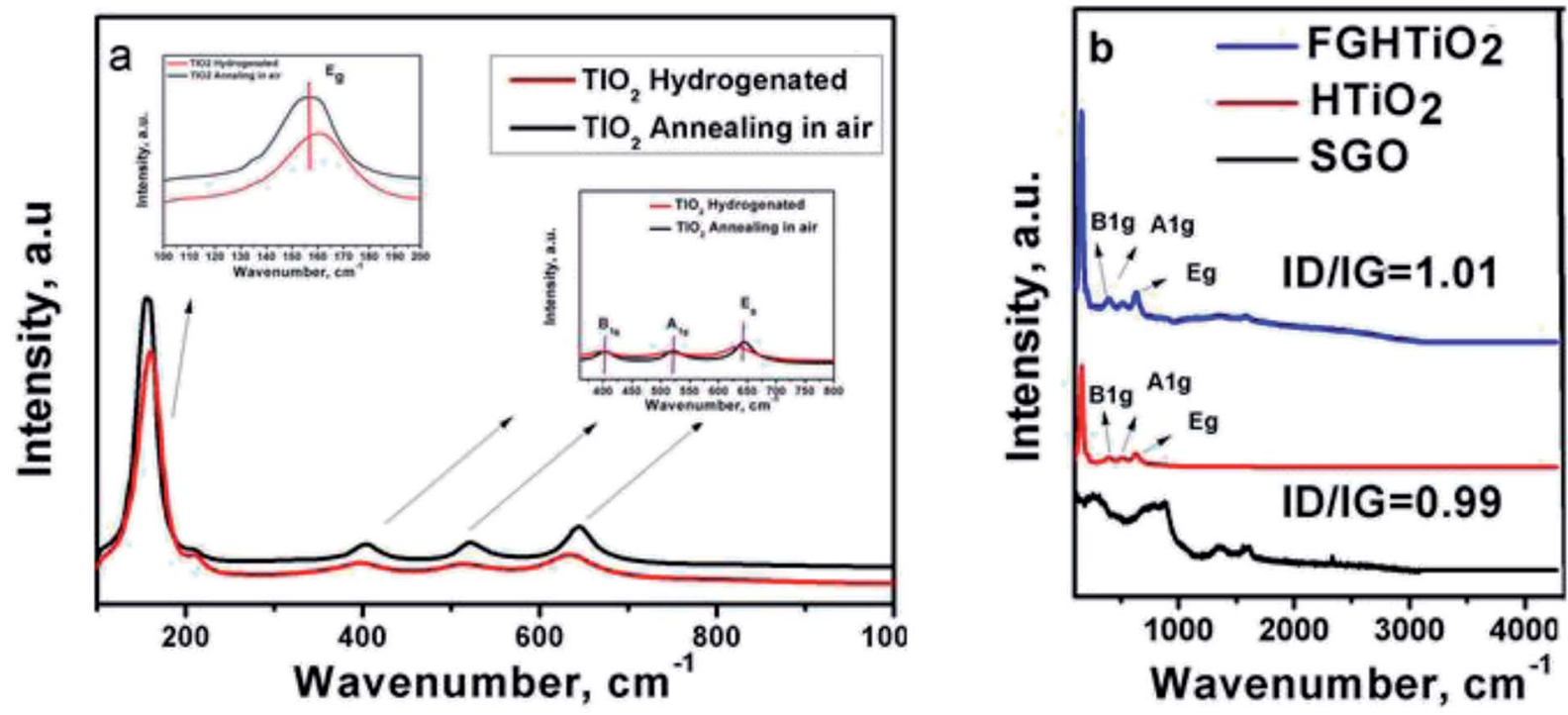

Fig. 4 Raman spectra of (a) air- and $\mathrm{H}_{2}$-annealed $\mathrm{TiO}_{2}$, and (b) pristine graphite, SGO, $\mathrm{FG}, \mathrm{HTIO}$, and $\mathrm{FG}-\mathrm{HTiO}$. 
the thermal treatment at temperatures less than $500{ }^{\circ} \mathrm{C}$. The third step is extended from $350{ }^{\circ} \mathrm{C}$ up to $800{ }^{\circ} \mathrm{C}$, resulting in a notable mass loss of $\sim 80 \%$, which can be attributed to the decomposition of carbonyl groups formed on the surface of graphene oxide to yield CO gas. ${ }^{33}$ FGO showed higher thermal stability than SGO. The first humiliation step of FGO appeared nearly in the similar range to that of SGO $\left(145-173^{\circ} \mathrm{C}\right)$, while the second step of the degradation appeared at a greatly higher temperature of $365-415^{\circ} \mathrm{C}$. Upon functionalization of SGO with adenine, the labile oxygen groups underwent chemical reaction to form a strong covalent bond with the amino groups of adenine, which noticeably decreased the volume of labile groups in FGO. This results in a very low weight loss at about 145-173 ${ }^{\circ} \mathrm{C}$ in FGO, which is in agreement with the decrease in the FTIR peak intensity at $1725 \mathrm{~cm}^{-1}$. This is typical due to the stretching vibrations $\nu(\mathrm{C}=\mathrm{O})$ of $\mathrm{COOH}$ group equivalent to carbonyl and carboxyl groups that have disappeared, with the peak emerged at $1637 \mathrm{~cm}^{-1}$ is characteristic of the $\mathrm{C}=\mathrm{O}$ stretching in the amide group,$^{34}$ see Fig. $3 \mathrm{~b}$. The weight loss of the hydrothermally reduced FG shows a slight weight loss of about $10 \%$ up to $670{ }^{\circ} \mathrm{C}$, indicating that the oxygen-based groups in GO formed heat-stable structures through covalent bonding with adenine. In the case of the $\mathrm{FG}^{-\mathrm{HTiO}_{2}}$ nanocomposite, the weight loss of the sample was greatly limited, which may indicate that FG imposed a control on the mobilization of titanium oxide nanotubes, leading to homogeneous heating and preventing heat concentration. This also supports a strong contact between FG and $\mathrm{H}-\mathrm{TiO}_{2}$.

To study supercapacitive performance of the fabricated samples, cyclic voltammetry (CV) measurements were performed in $0.5 \mathrm{M} \mathrm{H}_{2} \mathrm{SO}_{4}$, where the specific capacitance of the electrodes was calculated using eqn (1).

$$
C_{\mathrm{s}}=\frac{\int I \mathrm{~d} v}{\nu m \Delta V}
$$

where $C_{\mathrm{s}}$ is the specific capacitance, $m$ is the weight of the electrode $(\mathrm{g}), I$ is the response current density $\left(\mathrm{A} \mathrm{g}^{-1}\right), \Delta V$ is the potential difference, and $\nu$ is the potential scan rate $\left(\mathrm{mV} \mathrm{s}^{-1}\right)$. Fig. 6a shows a comparison of the cyclic voltammograms of SGO, FG-HT1, FG-HT2, FG-HT3 and FG-HT4 electrodes in the potential range of -0.2 to $1 \mathrm{~V}$ at a scan rate of $5 \mathrm{mV} \mathrm{s}^{-1}$. It was observed that with increasing $\mathrm{TiO}_{2}$ content, the specific capacitance firstly increases to a maximum value and then declines, with an optimum loading of $\mathrm{TiO}_{2}$ of $20 \mathrm{wt} \%$. Fig. $6 \mathrm{~b}$ shows that the specific capacitance decreases with increasing the scan rate from 1 to $25 \mathrm{mV} \mathrm{s}^{-1}$, which can be related to the insufficient time available for ion diffusion and adsorption inside the smallest pores within a large particle at high scan rates. The sudden drop in the capacitance of the FG-HT4 can be related to the presence of high concentration of $\mathrm{HTiO}_{2}$ that tend to agglomerate and block the pores of graphene, thus masking the effect of graphene nanosheets (GNS). In this case, the ions in the electrolyte might not have enough time to move into the complex micropores of the electrodes (diffusion limited) at high scan speeds. Note that the specific capacitance of the functionalized graphene- $\mathrm{HTiO}_{2}$ hybrid electrode was much higher than that of the SGO and FG electrodes, which is also higher than previous reports. ${ }^{35}$ This higher capacitance value can be ascribed to the faradaic and non-faradaic reactions arising from graphene and hydrogenated $\mathrm{TiO}_{2} \cdot{ }^{36,37}$ Also, the donor densities of $\mathrm{TiO}_{2}$ nanotubes are significantly improved by well-ordered introduction of oxygen vacancy $\left(\mathrm{Ti}^{3+}\right.$ sites) states through thermal treatment in hydrogen gas. ${ }^{38}$ Furthermore, we anticipate that hydroxyl groups will be introduced on $\mathrm{TiO}_{2}$ surface during hydrogenation, which could modify the electrochemical activity of $\mathrm{TiO}_{2}$ and therefore increase its pseudocapacitance, Fig. $6 \mathrm{c}$ and d. The specific capacitance of the FG-HT2 electrode reached is as high as $401 \mathrm{~F} \mathrm{~g}^{-1}$ at a scan rate of $1 \mathrm{mV} \mathrm{s}^{-1}$ and drops to $110.4 \mathrm{~F} \mathrm{~g}^{-1}$ at a scan rate of $100 \mathrm{mV} \mathrm{s}^{-1}$, which again implies that the ions in the electrolyte might not have enough time to enter into the complex micropores of the electrodes (diffusion limited) at high scan speeds, Fig. 6e. Note that the obtained specific capacitance of $401 \mathrm{~F} \mathrm{~g}^{-1}$ at a scan rate of $1 \mathrm{mV}$ $\mathrm{s}^{-1}$ is much higher than that previously reported for graphene$\mathrm{TiO}_{2}$ electrodes $\left(165 \mathrm{~F} \mathrm{~g}^{-1}\right.$ at $1 \mathrm{M} \mathrm{Na}_{2} \mathrm{SO}_{4}$ at $\left.5 \mathrm{mV} \mathrm{s}^{-1}\right) .^{39,40}$

Galvanostatic charge/discharge measurements are necessary to determine the electrochemical performance of all material to be used as supercapacitors. The specific capacitance was calculated at different current densities using eqn (2)

$$
C_{\mathrm{s}}=\frac{I \Delta t}{m \Delta V}
$$

where $I$ is the discharge current (A), $\Delta t$ is the discharge time (s), and $\Delta V$ is the potential window $(\mathrm{V})$.

Fig. 7a shows a comparison of the galvanostatic charge/ discharge graphs for $\mathrm{FG}$ and $\mathrm{FG}-\mathrm{HTiO}_{2}$ at $2 \mathrm{~A} \mathrm{~g}^{-1}$ current density. The FG-HTiO ${ }_{2}$ nanocomposite achieved better specific capacitance $\left(375 \mathrm{~F} \mathrm{~g}^{-1}\right.$ at a $1 \mathrm{~A} \mathrm{~g}^{-1}$ ) than FG at the same current density. Fig. 7b shows the galvanostatic charge/discharge graphs of the fabricated $\mathrm{FG}-\mathrm{HTiO}_{2}$ at different current densities (0.8-3 $\left.\mathrm{A} \mathrm{g}^{-1}\right)$. All the charge-discharge curves are quasitriangular, indicating fast and capable charge transfer and high electrical conductivity. ${ }^{41}$ This can be attributed to the presence of active nitrogen atoms from adenine and the high electronegativity of nitrogen as well as the hydrogenated titanium dioxide that may create dipoles on the surface of graphene,${ }^{\mathbf{4 1 , 4 2}}$ which may draw charged species into the surface. ${ }^{\mathbf{4 3 , 4 4}}$ The influence of $\mathrm{N}, \mathrm{O}$ atoms and $\mathrm{HTiO}_{2}$ on the capacitance can also be ascribed to the inductive effect of the $\sigma$-bonded structure from $\mathrm{N}$, O heteroatoms and hydrogenated titania, which help in the polarization of some bonds and distribution of electrons on the surface, resulting in reversible faradaic redox reactions. ${ }^{45}$ Fig. 7c presents relationship between the specific capacitance and current density, where a decrease in specific capacitance is observed as the current density increases. The calculated specific capacitances obtained from charge and discharge curves of $\mathrm{FG}^{-} \mathrm{HTiO}_{2}$ are 393.3, 375, 261.6, and 202.5 F $\mathrm{g}^{-1}$ at $0.8,1,2$ and $3 \mathrm{~A} \mathrm{~g}^{-1}$, respectively. Note that the obtained specific capacitance at $0.8 \mathrm{~A} \mathrm{~g}^{-1}\left(393.3 \mathrm{~F} \mathrm{~g}^{-1}\right)$ is very close to that calculated from the cyclic voltammograms $\left(401 \mathrm{~F} \mathrm{~g}^{-1}\right)$, which is much higher than that previously reported for graphene/ $\mathrm{TiO}_{2}$ hybrid electrodes. ${ }^{\mathbf{4 6}}$ Moreover, the $\mathrm{FG}^{-} \mathrm{HTiO}_{2}$ electrode exhibits excellent rate capability of $51.5 \%$ at a current density of $3 \mathrm{~A} \mathrm{~g}^{-1}$. The energy and power densities are very important performance 

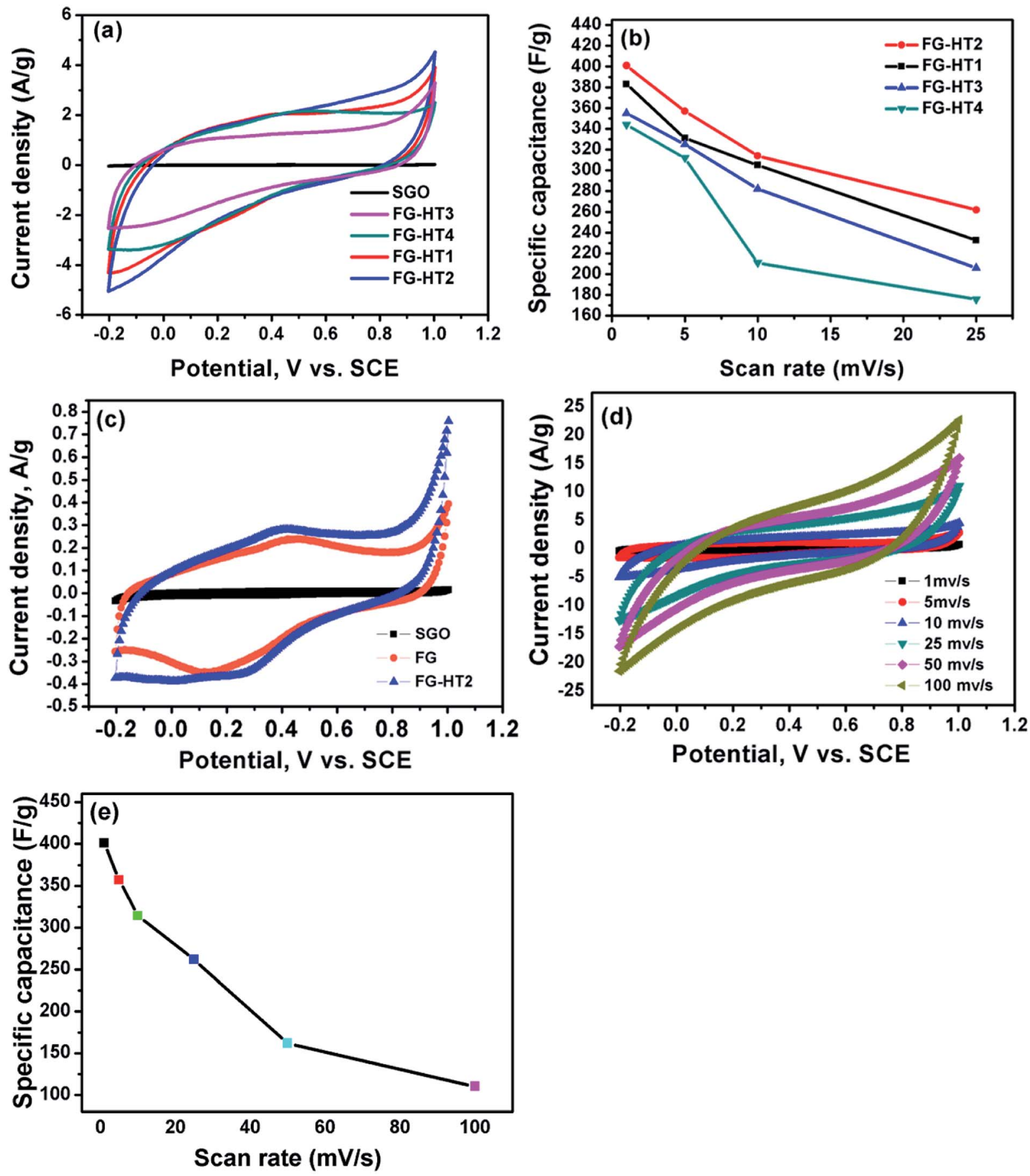

Fig. 6 (a) Comparative cyclic voltammograms of FG-H1, FG-H2, FG-H3 and FG-H4 nanocomposite at a scan rate of $5 \mathrm{mV} \mathrm{s}^{-1}$, (b) average specific capacitances of FG-HT1, FG-HT2, FG-HT3 and FG-HT4 nanocomposites at various scan rates of 1, 5, 10 and $25 \mathrm{mV} \mathrm{s}^{-1}$, (c) comparative cyclic voltammograms of FG-HT2, FG and SGO electrodes at a scan rate of $5 \mathrm{mV} \mathrm{s}^{-1}$, (d) cyclic voltammograms of FG- $\mathrm{H} 2$ electrodes at different scan rates, and (e) the corresponding specific capacitance of FG- $\mathrm{H} 2$ electrodes at different scan rates in $0.5 \mathrm{M} \mathrm{H}_{2} \mathrm{SO}_{4}$.

metrics of supercapacitors, which can be calculated from the galvanostatic charge/discharge graphs using eqn (3) and (4):

$$
\begin{gathered}
E=\frac{1}{2} C_{\mathrm{s}}(\Delta V)^{2}=\frac{I \Delta V t}{2 m} \\
P=\frac{E}{t}=\frac{I \Delta V}{m}
\end{gathered}
$$

where $E$ and $P$ refer of the average energy density $\left(\mathrm{W} \mathrm{h} \mathrm{kg}^{-1}\right)$ and average power density $\left(\mathrm{W} \mathrm{kg}{ }^{-1}\right)$, respectively, and $C_{\mathrm{s}}$ is the specific capacitance calculated from the charge/discharge curves, $I$ is the discharge current (A), $t$ is the discharge time (h), $\Delta V$ is the potential window (V), and $m$ is the mass of the FG$\mathrm{HTiO}_{2}$ electrode $(\mathrm{kg})$. 

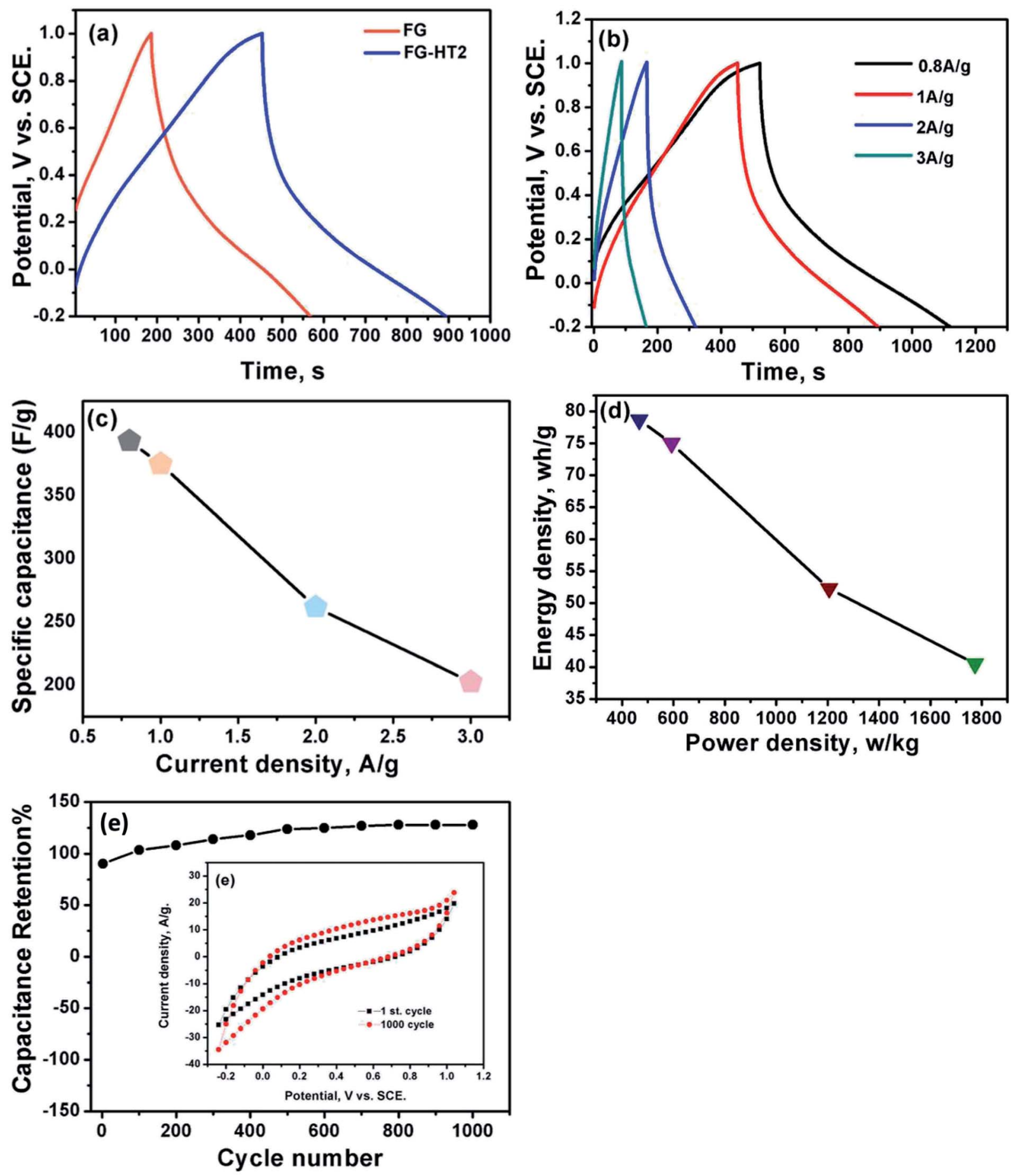

Fig. 7 (a) Comparative galvanostatic charge/discharge plots of $\mathrm{FG}$ and $\mathrm{FG}-\mathrm{H} 2$ nanocomposite at a current density of $2 \mathrm{~A} \mathrm{~g}^{-1}$, (b) galvanostatic charge/discharge of FG-H2 at different current densities of $0.8,1,2$ and $3 \mathrm{~A} \mathrm{~g}^{-1}$, (c) the corresponding specific capacitance of FG-H2 electrode, (d) Ragone plot at different current densities of $0.8,1,2$, and $3 \mathrm{~A} \mathrm{~g}^{-1}$, and (e) the first and 1000th CV cycles at a scan rate of $100 \mathrm{mV} \mathrm{s}{ }^{-1}$ of FG-H2 electrodes in $0.5 \mathrm{M} \mathrm{H}_{2} \mathrm{SO}_{4}$.

Ragone's plot for the FG-HTiO 2 electrode at different current densities is shown in Fig. $7 d$. The energy density can reach up to $78.66 \mathrm{~W} \mathrm{~h} \mathrm{~kg}^{-1}$ with a power density of $466.9 \mathrm{~W} \mathrm{~kg}^{-1}$ at $0.8 \mathrm{~A} \mathrm{~g}^{-1}$. It is worthy to mention that the achieved energy density for $\mathrm{FG}^{-} \mathrm{HTiO}_{2}$ electrode $\left(78.66 \mathrm{~W} \mathrm{~h} \mathrm{~kg}^{-1}\right)$ at $0.8 \mathrm{~A} \mathrm{~g}^{-1}$ is much higher than those reported for graphene-based electrodes fabricated by different methods. ${ }^{23,47-50}$ Fig. 7e shows the cycle life test of the FG-HTiO 2 performed at a scan rate of $100 \mathrm{mV} \mathrm{s}^{-1}$ for 1000 cycles. The specific capacitance sharply increased from the initial cycle until 1000 cycle to reach $100.2 \%$ of the initial cycle, indicating the excellent cycling stability of the $\mathrm{FG}-\mathrm{HTiO}_{2}$ electrodes. Table 1 compares the obtained results to those 
Table 1 Comparison of the obtained specific capacitance with those reported in literature

\begin{tabular}{llll}
\hline Material & Synthetic approach & Specific capacitance \\
\hline Graphene/TiO & Ref. \\
Coating of $\mathrm{TiO}_{2}$ on graphene & Microwave-assisted technique & $165 \mathrm{~F} \mathrm{~g}^{-1}$ in $1 \mathrm{M} \mathrm{Na}_{2} \mathrm{SO}_{4}$ & 39 \\
Sulfonated graphene/ $/ \mathrm{MnO}_{2} / \mathrm{PANI}$ & Atomic layer deposition (ALD) & $75 \mathrm{~F} \mathrm{~g}^{-1}$ and $84 \mathrm{~F} \mathrm{~g}^{-1}$ in a $1 \mathrm{M} \mathrm{KOH}$ \\
$\mathrm{CoFe}_{2} \mathrm{O}_{4} / \mathrm{rGO} / \mathrm{PANI}$ & Polymerization reaction & $276 \mathrm{~F} \mathrm{~g}^{-1}$ in $1 \mathrm{M} \mathrm{Na}_{2} \mathrm{SO}_{4}$ & 51 \\
$\mathrm{Graphene}_{\mathrm{MnO}} / \mathrm{PANI}$ & Polymerization reaction & $257 \mathrm{~F} \mathrm{~g}^{-1}$ in $1 \mathrm{M} \mathrm{KOH}$ & 53 \\
$\mathrm{Graphene}_{\mathrm{MnO}} / \mathrm{PANI}$ & Polymerization reaction & $380 \mathrm{~F} \mathrm{~g}^{-1}$ in $0.5 \mathrm{M} \mathrm{Na}_{2} \mathrm{SO}_{4}$ & 54 \\
Black titania/spongy graphene & Polymerization reaction & $395 \mathrm{~F} \mathrm{~g}^{-1}$ in $1 \mathrm{M} \mathrm{H}_{2} \mathrm{SO}_{4}$ & 55 \\
& Hydrothermal process & $401 \mathrm{~F} \mathrm{~g}^{-1}$ in $0.5 \mathrm{M} \mathrm{H}_{2} \mathrm{SO}_{4}$
\end{tabular}

reported in literature, showing the superiority of our fabricated hybrid electrodes.

\section{Conclusions}

A simple method is demonstrated to prepare functionalized spongy graphene/hydrogenated titanium dioxide $\left(\mathrm{FG}-\mathrm{HTIO}_{2}\right)$ nanocomposite electrodes. The electron microscopy (FESEM and TEM) study showed the formation hydrogenated titanium nanotubes $\mathrm{H}-\mathrm{TiO}_{2}$ NTs that are grown onto FG sheets. This was supported by the XRD analysis. Also, the FTIR spectra showed a peak at $3475 \mathrm{~cm}^{-1}$ that is attributed to the $\mathrm{OH}$ and $\mathrm{NH}$ stretching groups, confirming the covalent functionalization of the neat graphene by adenine, and a peak at $588 \mathrm{~cm}^{-1}$ indicating the Ti-O-C vibration. The higher $I_{\mathrm{D}} / I_{\mathrm{G}}$ ratio in the Raman spectra of $\mathrm{FG}-\mathrm{HTiO}_{2}$ (1.01) than that of GO (0.99) indicates the reduction in the size of the in-plane $\mathrm{sp}^{2}$ domains. Also, the notable bands located at $147\left(\mathrm{E}_{\mathrm{g}}\right), 402\left(\mathrm{~B}_{1 \mathrm{~g}}\right), 513\left(\mathrm{~A}_{1 \mathrm{~g}}\right)$ and $(635$ $\mathrm{E}_{\mathrm{g}}$ ) as well as the small peaks at $159 \mathrm{~cm}^{-1}$ are attributed to intercalated $\mathrm{TiO}_{2}$ nanotubes, thus confirming the formation of the $\mathrm{FG}^{-} \mathrm{HTiO}_{2}$ structure. The TGA analysis of the $\mathrm{FG}-\mathrm{HTiO}_{2}$ showed a slight weight loss at $670{ }^{\circ} \mathrm{C}$. Upon their use as

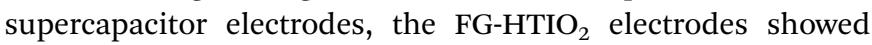
a maximum specific capacitance of $401 \mathrm{~F} \mathrm{~g}^{-1}$ at scan rate of $1 \mathrm{mV} \mathrm{s}^{-1}$ and exhibited excellent cycling retention of $100.2 \%$ after 1000 cycles at $100 \mathrm{mV} \mathrm{s}^{-1}$. The energy density was $75 \mathrm{~W} \mathrm{~h} \mathrm{~kg}^{-1}$ with a power density of $592.4 \mathrm{~W} \mathrm{~kg}^{-1}$ at $1 \mathrm{~A} \mathrm{~g}^{-1}$. These results demonstrate that the fabricated $\mathrm{FG}^{-} \mathrm{HTiO}_{2}$ hybrid electrodes are promising electrode materials for highperformance supercapacitors. The specific capacitance improved due to the synergistic effects of the spongy graphene structure, hydrogenated titania and the presence of adenine.

\section{Conflicts of interest}

The authors declare no competing financial interest.

\section{Acknowledgements}

The authors acknowledge the financial support of the work by the American University in Cairo and the National Research Centre.

\section{References}

1 D. M. El-Gendy, N. A. A. Ghany, E. F. El Sherbini and N. K. Allam, Green, single-pot synthesis of functionalized $\mathrm{Na} / \mathrm{N} / \mathrm{P}$ co-doped graphene nanosheets for highperformance supercapacitors, J. Electroanal. Chem., 2019, 837, 30-38.

2 A. G. Pandolfo and A. F. Hollenkamp, Carbon properties and their role in supercapacitors, J. Power Sources, 2006, 157, 11.

3 M. Ramadan, A. M. Abdellah, S. G. Mohamed and N. K. Allam, 3D interconnected binder free electrospun MnO@C nanofibers for supercapacitor devices, Sci. Rep., 2018, 8, 7988.

4 A. E. Elkholy, F. E. Heakal and N. K. Allam, Nanostructured spinel manganese cobalt ferrite for high-performance supercapacitors, RSC Adv., 2017, 7, 51888-51895.

5 A. E. Elkholy, F. E. Heakal and N. K. Allam, A facile electrosynthesis approach of amorphous Mn-Co-Fe ternary hydroxides as binder-free active electrode materials for high performance supercapacitors, Electrochim. Acta, 2019, 296, 59-68.

6 F. M. Ismail, M. Ramadan, A. M. Abdellah, I. Ismail and N. K. Allam, Mesoporous spinel manganese zinc ferrite for high-performance supercapacitors, J. Electroanal. Chem., 2018, 817, 111-117.

7 M. A. Mohamed, D. M. El-Gendy, N. Ahmed, C. E. Banks and N. K. Allam, 3D spongy graphene-modified screen-printed sensors for the voltammetric determination of the narcotic drug codeine, Biosens. Bioelectron., 2018, 101, 90-95.

8 D. Wei, Y. Liu, H. Zhang, L. Huang, B. Wu, J. Chen and G. Yu, Scalable synthesis of few layer graphene ribbons with controlled morphologies by a template method and their applications in nanoelectromechanical switches, J. Am. Chem. Soc., 2009, 131, 11147-11154.

9 T. Kim, G. Jung, S. Yoo, K. S. Suh and R. S. Ruoff, Activated graphene-based carbons as supercapacitor electrodes with macro- and mesopores, ACS Nano, 2013, 7, 6899-6905.

10 N. Ahmed, M. Ramadan, W. M. A. El Rouby, A. A. Farghali and N. K. Allam, Non-precious co-catalysts boost the performance of $\mathrm{TiO}_{2}$ hierarchical hollow mesoporous spheres in solar fuel cells, Int. J. Hydrogen Energy, 2018, 43, 21219-21230.

11 B. A. Ali, O. I. Metwalli, A. S. G. Khalil and N. K. Allam, Unveiling the effect of the structure of carbon material on 
the charge storage mechanism in $\mathrm{MoS}_{2}$-based supercapacitors, ACS Omega, 2018, 3, 16301-16308.

12 S. G. Mohamed, S. Y. Attia and N. K. Allam, One-step, Calcination-free Synthesis of Zinc Cobaltite Nanospheres for High-performance Supercapacitors, Mater. Today Energy, 2017, 4, 97-104.

13 X. Deng, J. Li, S. Zhu, F. He, C. He, E. Liu, C. Shi, Q. Li and N. Zhao, Metal-organic frameworks-derived honeycomblike $\mathrm{Co}_{3} \mathrm{O}_{4} /$ three-dimensional graphene networks/Ni foam hybrid as a binder-free electrode for supercapacitors, $J$. Alloys Compd., 2017, 693, 16-24.

14 D. R. Dreyer, R. S. Ruoff and C. W. Bielawski, From conception to realization: an historical account of graphene and some perspectives for its future, Angew. Chem., Int. Ed., 2010, 49(49), 9336-9344.

15 F. Liu, C. W. Lee and J. S. Im, Graphene-based carbon materials for electrochemical energy storage, J. Nanomater., 2013, 642915.

16 H. Ren, M. Tang, B. Guan, K. Wang and J. Yang, Hierarchical graphene foam for efficient omnidirectional solar-thermal energy conversion, Adv. Mater., 2017, 29(38), 1702590.

17 T. Kuila, S. Bose, A. K. Mishra, P. Khanra, N. H. Kim and J. H. Lee, Chemical functionalization of graphene and its applications, Prog. Mater. Sci., 2012, 57(7), 1061-1105.

18 O. C. Compton and S. T. Nguyen, Graphene oxide, highly reduced graphene oxide, and graphene: versatile building blocks for carbon-based materials, Small, 2010, 6(6), 711723.

19 W. S. Hummers and R. E. Offeman, Preparation of graphitic oxide, J. Am. Chem. Soc., 1958, 80, 1339.

$20 \mathrm{X}$. Yang, K. Xu, R. Zou and J. Hu, A hybrid electrode of $\mathrm{Co}_{3} \mathrm{O}_{4} @ P P y$ core/shell nanosheet arrays for highperformance supercapacitors, Nano-Micro Lett., 2016, 8(2), 143-150.

21 B. Zhang, F. Wang, C. Zhu, Q. Li, J. Song, M. Zheng, L. Ma and W. Shen, A facile self-assembly synthesis of hexagonal $\mathrm{ZnO}$ nanosheet films and their photoelectrochemical properties, Nano-Micro Lett., 2016, 8(2), 137-142.

22 N. L. Torad, R. R. Salunkhe, Y. Li, H. Hamoudi, M. Imura, Y. Sakka, C. C. Hu and Y. Yamauchi, Electric double-layer capacitors based on highly graphitized nanoporous carbons derived from ZIF-67, Chem.-Eur. J., 2014, 20(26), 7895-7900.

23 D. M. El-Gendy, N. A. A. Ghany, E. F. El Sherbini and N. K. Allam, Adenine-functionalized Spongy Graphene for Green and High-Performance Supercapacitors, Sci. Rep., 2017, 70, 43104.

24 F. Narges and F. T. Sekino, A Novel Method for Synthesis of Titania Nanotube Powders using Rapid Breakdown Anodization, Chem. Mater., 2009, 21, 1967-1979.

25 K. M. Mackay, Hydrogen Compounds of the Metallic Elements, E and FN Spon, London, UK, 1966, p. 71.

26 M. M. Soliman, M. H. Al Haron, M. Samir, S. A. Tolba, B. S. Shaheen, A. W. Amer, O. F. Mohammed and N. K. Allam, On the relationship between rutile/anatase ratio and the nature of defect states in sub-100 $\mathrm{nm} \mathrm{TiO}_{2}$ nanostructures: experimental insights, Phys. Chem. Chem. Phys., 2018, 20, 5975-5982.

27 X. Chen, L. Liu, Z. Liu, M. A. Marcus, W. C. Wang, N. A. Oyler, M. E. Grass, B. Mao, P.-A. Glans, P. Y. Yu, J. Guo and S. S. Mao, Properties of disorder-engineered black titanium dioxide nanoparticles through hydrogenation, Sci. Rep., 2013, 3, 1510.

28 H. Zhang, X. J. Lv, Y. M. Li, Y. Wang and J. H. Li, P25graphene composite as a high performance photocatalyst, ACS Nano, 2010, 4, 380-386.

29 X. Liu, H. Xu, L. R. Grabstanowicz, S. Gao, Z. Lou, W. Wang, B. Huang, Y. Dai and T. Xu, $\mathrm{Ti}^{3+}$ self-doped $\mathrm{TiO}_{2-\mathrm{x}}$ anatase nanoparticles via oxidation of $\mathrm{TiH}_{2}$ in $\mathrm{H}_{2} \mathrm{O}_{2}$, Catal. Today, 2014, 225, 80-89.

30 S. Liu, C. Liu, W. Wang, B. Cheng and J. Yu, Unique photocatalytic oxidation reactivity and selectivity of $\mathrm{TiO}_{2}-$ graphene composites, Nanoscale, 2012, 4, 3193-3200.

31 G. Wang, H. Wang, Y. Ling, Y. Tang, X. Yang, R. C. Fitzmorris, C. Wang, J. Z. Zhang and L. Yat, Hydrogen- treated $\mathrm{TiO}_{2}$ nanowire arrays for photoelectrochemical water splitting, Nano Lett., 2011, 11(7), 3026-3033.

32 C. D. Zangmeister, Preparation and evaluation of graphite oxide reduced at $220^{\circ} \mathrm{C}$, Chem. Mater., 2010, 22, 5625.

33 Z. Lei, L. Lu and X. S. Zhao, The electrocapacitive properties of graphene oxide reduced by urea, Energy Environ. Sci., 2012, 5, 6391.

34 H. Yang, F. Li, C. Shan, D. Han, Q. Zhang, L. Niu and A. Ivaska, Covalent functionalization of chemically converted graphene sheets via silane and its reinforcement, J. Mater. Chem., 2009, 19, 4632-4638.

35 L.-B. Xing, S.-F. Hou, J. Zhou, J.-L. Zhang, W. Si, Y. Dong and S. Zhuo, Three dimensional nitrogen-doped graphene aerogels functionalized with melamine for multifunctional applications in supercapacitors and adsorption, J. Solid State Chem., 2015, 230, 224-232.

36 D. Hulicova-Jurcakova, M. Seredych, G. Q. Lu, N. K. A. C. Kodiweera, P. E. Stallworth, S. Greenbaum and T. J. Bandosz, Effect of surface phosphorus functionalities of activated carbons containing oxygen and nitrogen on electrochemical capacitance, Carbon, 2009, 47, 1576-1584.

37 C. H. Choi, S. H. Park and S. I. Woo, Heteroatom doped carbons prepared by the pyrolysis of bio-derived amino acids as highly active catalysts for oxygen electro-reduction reactions, Green Chem., 2011, 13, 406-412.

38 D. Choi, G. E. Blomgren and P. N. Kumta, Fast and Reversible Surface Redox Reaction in Nanocrystalline Vanadium Nitride Supercapacitors, Adv. Mater., 2006, 18(9), 1178-1182.

39 A. K. Geim and K. S. Novoselov, The rise of graphene, Nat. Mater., 2007, 6(3), 183-191, DOI: 10.1038/nmat1849.

40 C. Xiang, M. Li, M. Zhi, A. Manivannan and N. Wu, Reduced graphene oxide/titanium dioxide composites for supercapacitor electrodes: shape and coupling effects, $J$. Mater. Chem., 2012, 22, 19161-19167.

41 Z. S. Wu, K. Parvez, A. Winter, H. Vieker, X. Liu, S. Han, A. Turchanin, X. Feng and K. üllen, Layer-by-layer 
assembled hetero atom-doped graphene films with ultrahigh volumetric capacitance and rate capability for micro-supercapacitors, Adv. Mater., 2014, 26, 4552-4558.

42 L. Sun, C. Tian, M. Li, X. Meng, L. Wang, R. Wang, J. Yin and H. Fu, From coconut shell to porous graphene-like nano sheets for high-power super- capacitors, J. Mater. Chem. A, 2013, 1, 6462-6470.

43 J. H. U. Z. Kang, F. Li and X. Huang, Graphene with threedimensional architecture for high performance supercapacitor, Carbon, 2014, 67, 221-229.

$44 \mathrm{H}$. Wang, T. Maiyalagan and X. Wang, Review on recent progress in nitrogen- doped graphene, synthesis, characterization, and its potential applications, ACS Catal., 2012, 2, 781-794.

45 X. Sun, M. Xie, G. Wang, H. Sun, A. S. Cavanagh, J. J. Travis, S. M. George and J. Lian, Atomic layer deposition of $\mathrm{TiO}_{2}$ on graphene for supercapacitors, J. Electrochem. Soc., 2012, 159(4), A364-A369.

46 C. M. Chen, Q. Zhang, X. C. Zhao, B. Zhang, Q. Q. Kong, M. G. Yang, Q. H. Yang, M. Z. Wang, Y. G. Yang, R. Schlögl and D. S. Su, Hierarchically aminated graphene honey combs for electro- chemical capacitive, energy storage, $J$. Mater. Chem., 2012, 22, 14076-14084.

47 A. Ramadoss and S. J. Kim, Improved activity of a graphene$\mathrm{TiO}_{2}$ hybrid electrode in an electrochemical supercapacitor, Carbon, 2013, 63, 434-445.

48 C. M. Chen, Q. Zhang, M. G. Yang, C. H. Huang, Y. G. Yang and M. Z. Wang, Structural evolution during annealing of thermally reduced graphene nanosheets for application in supercapacitors, Carbon, 2012, 50, 3572.
49 S. Y. Yang, K. H. Chang, H. W. Tien, Y. F. Lee, S. M. Li, Y. S. Wang, J. Y. Wang, C. C. M. Ma and C. C. Hu, Design and tailoring of a hierarchical graphene-carbon nanotube architecture for supercapacitors, J. Mater. Chem., 2011, 21, 2374 .

50 Z. Lei, N. Christov and X. S. Zhao, Intercalation of mesoporous carbon spheres between reduced graphene oxide sheets for preparing high-rate supercapacitor electrodes, Energy Environ. Sci., 2011, 4, 1866.

51 X. Sun, M. Xie, G. Wang, H. Sun, A. S. Cavanagh, J. J. Travis, S. M. George and J. Lian, Atomic Layer Deposition of $\mathrm{TiO}_{2}$ on Graphene for Supercapacitors, J. Electrochem. Soc., 2012, 159, A364-A369.

52 G. Wang, Q. Tang, H. Bao, X. Li and G. Wang, Synthesis of hierarchical sulfonated graphene/ $\mathrm{MnO}_{2} /$ polyaniline ternary composite and its improved electrochemical performance, J. Power Sources, 2013, 241, 231-238.

53 K. Vijaya Sankar and R. Kalai Selvan, Fabrication of flexible fiber supercapacitor using covalently grafted $\mathrm{CoFe}_{2} \mathrm{O}_{4} /$ reduced graphene oxide/polyaniline and its electrochemical performances, Electrochim. Acta, 2016, 213, 469-481.

54 G. Yu, L. Hu, N. Liu, H. Wang, M. Vosgueritchian, Y. Yang, et al., Enhancing the supercapacitor performance of graphene $/ \mathrm{MnO}_{2}$ nanostructured electrodes by conductive wrapping, Nano Lett., 2011, 11, 4438-4442.

55 B. $\mathrm{Mu}, \mathrm{W}$. Zhang, S. Shao and A. Wang, Glycol assisted synthesis of graphene- $\mathrm{MnO}_{2}$-polyaniline ternary composites for high performance supercapacitor electrodes, Phys. Chem. Chem. Phys., 2014, 16, 7872-7880. 